(C) 2007 CORNELL UNIVERSITY

DOI: $10.1177 / 0010880407300158$

Volume 48, Issue $4 \quad 370-379$

\title{
How Organizational
}

Standards and

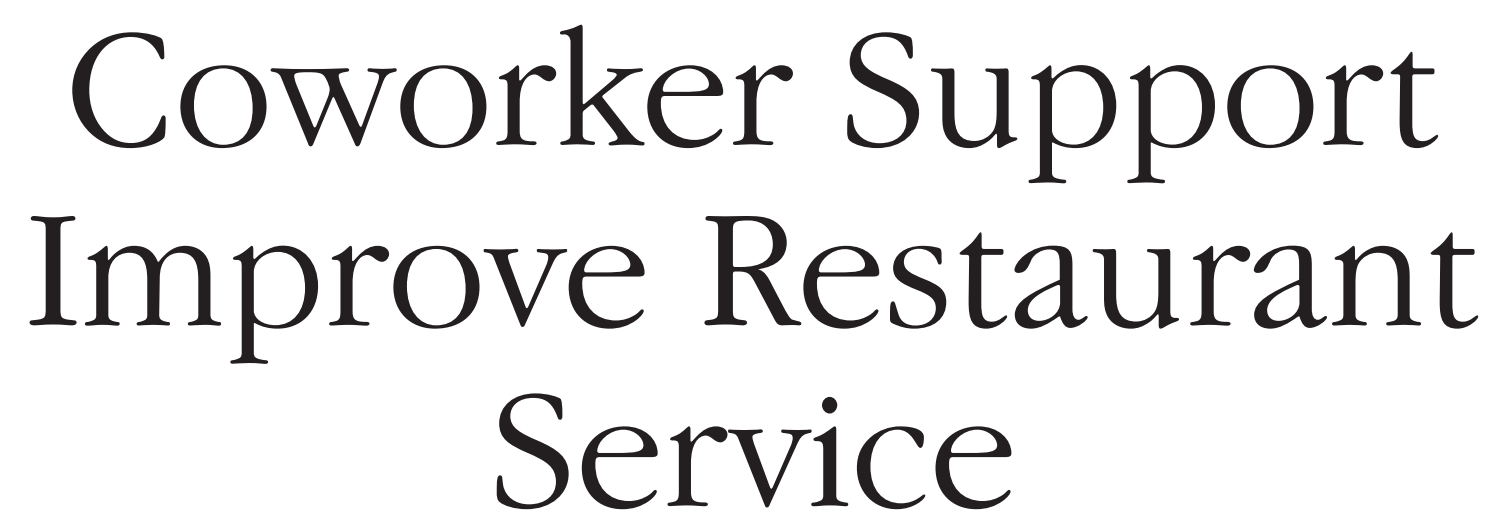

by ALEX M. SUSSKIND, K. MICHELE KACMAR, and CARL P. BORCHGREVINK

A model examining the relationship between restaurant employees' reactions to their work environment and their jobs as service providers and guest satisfaction was tested among twenty-five restaurants from a casual dining restaurant chain. In the model, the relationship between guest service employees' work-related perceptions and attitudes are connected to guests' reported satisfaction. Results show that employees' perceptions of the presence of organizational standards for service delivery were strongly related to their perceptions of receiving adequate support from coworkers and supervisors to perform their jobs. Employees' perceived support from coworkers was significantly related to service providers' guest orientation (commitment to their guests), while perceived support from supervisors proved to be a weak influence on guest orientation. Ultimately, service providers' guest orientation was strongly related to guests' satisfaction with their service experience in the restaurant.

Keywords: restaurant management; service quality; servers' attitudes; guest satisfaction 
$\mathrm{R}$ estaurant service is a process that is mutually created by three groups of individuals: managers (including owners), workers, and guests (Susskind, Kacmar, and Borchgrevink 2003). Because service is complex, the process is influenced by guest-related variables, such as demographics or behavior; service-provider variables, such as demographics, behavior, mood, and emotion; and the context, such as the organizational environment, structure, leadership, and coworkers (Ford and Etienne 2003).

As a method of describing how service providers and guests respond to the service process, Hogan, Hogan, and Busch (1984) used the term service orientation in the 1980s. They described service orientation as "a set of attitudes and behaviors that affects the staff of any organization and its guests" (p. 167). In the 1990s, Schneider, White, and Paul $(1998,153)$ described service orientation as service practices that assess "the degree to which an organization emphasizes, in multiple ways, meeting guest needs and expectations for service quality." These definitions, termed customer orientation or guest orientation, have been applied to the hospitality business to represent the extent to which service providers are committed to their guests (Susskind, Kacmar, and Borchgrevink 2003; Susskind et al. 2000). Regardless of the specific term, the underlying concept is that line-level employees have an important influence on the guest's experience. Exactly how service-oriented behavior and attitudes among line-level employees translate into guest satisfaction is less clear, particularly regarding restaurant experiences.

\section{The Guest-Server Exchange (GSX) Model}

To highlight this important area of guest service research for restaurant operators, we present in this article a test of a model of guest-server interaction in a group of chain restaurants (adapted from Susskind, Kacmar, and Borchgrevink 2003; Susskind et al. 2000). In the model presented here, we suggest that organizational standards for service form the foundation and guidelines for service providers to perform their jobs. Based on those standards, service providers then receive support from their coworkers and supervisors, which has the effect of creating a positive service atmosphere. That positive service atmosphere fosters guest satisfaction.

The model begins with employees' perceptions of organizational standards for service delivery (as shown in Exhibit 1). Standards for service delivery are antecedents to employees' perceptions of coworkers' and supervisors' support. That support in turn leads to service workers' guest orientation. Last, frontline service workers' guest orientation promotes guests' reported satisfaction with their service experience.

\section{Organizational Standards}

Organizational standards for service delivery are a key influence on employees' behavior and outcomes in organizations. Standards in this context consist of (1) organizational goals and objectives; (2) managerial expectations for job performance; and (3) the implicit importance placed on those goals, objectives, and performance demands (Litwin and Stringer 1968). In service organizations, line-level employees are responsible for the bulk of interaction with guests. Frontline employees thus constitute the direct link between an organization's operational mission and its guests (Grisaffe 2000). Consequently, an organization must have standards in place to guide, direct, and monitor the service behavior of line-level employees and those who supervise them (Susskind, Kacmar, and Borchgrevink 2003; Susskind et al. 2000). 


\section{Exhibit 1:}

Proposed Model of the Guest Service Processes and Organizational Outcomes

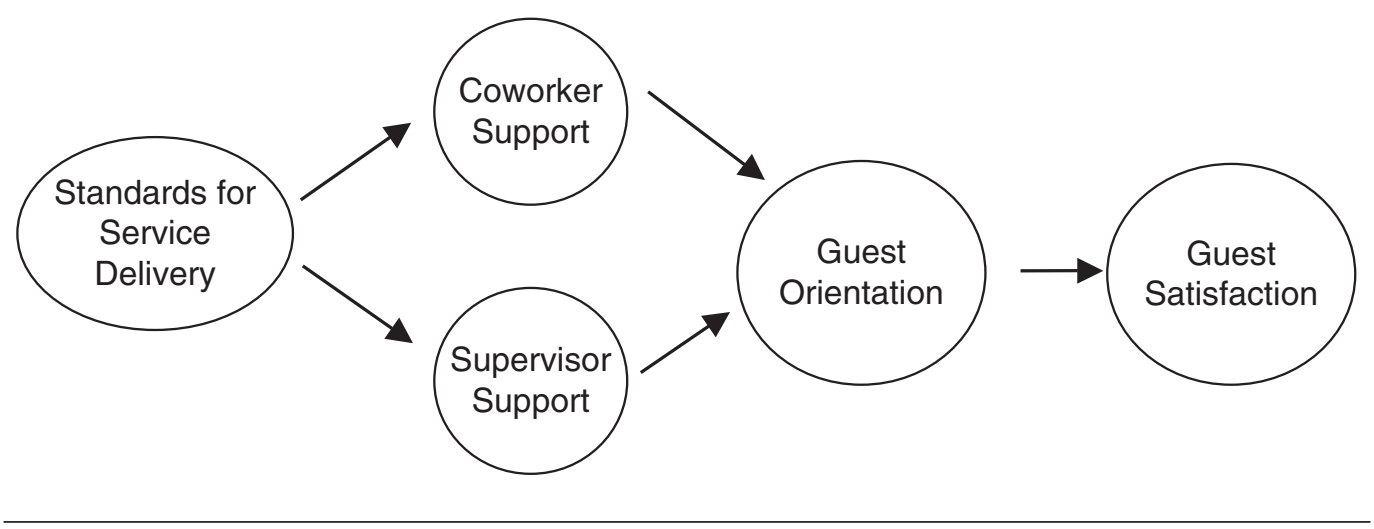

Standards for service are an important part of an organization's mission because they provide the foundation on which services are produced, delivered, and evaluated. Research has shown that managerial philosophies and values behind an organization's internal business practices influence the actions of both service personnel and guests (Grisaffe 2000). In that regard, support from managers can improve employees' well being and performance (Schmit and Allscheid 1995).

A study by Armeli and colleagues (1998) found that employees' perceptions of organizational support are stronger when employees believe they are being guided by a strong set of standards (see also Eisenberger et al. 1997; Susskind, Kacmar, and Borchgrevink 2003; Susskind et al. 2000). While the strong presence of standards has been shown to promote the GSX, additional support is needed, as standards alone do not guarantee appropriate service.

\section{Perceptions of Support}

If standards set the stage for desired performance, service personnel will likely use them as a guide. Support functions in service-based organizations have been shown to come from two main sources: (1) support from coworkers and (2) support from supervisors or management (Susskind, Kacmar, and Borchgrevink 2003; Susskind et al. 2000). Separating support functions into coworker and supervisory parts emphasizes the fact that line-level employees and their supervisors play distinct but essential support roles in the GSX. In this framework, coworker support is defined as the extent to which employees believe their coworkers provide them with work-related assistance to aid them in carrying out their service-related duties (Susskind, Kacmar, and Borchgrevink 2003; Susskind et al. 2000). By the same token, supervisory support is defined as the extent to which employees believe that their supervisors offer them work-related help in performing their jobs as service workers (Susskind, Kacmar, and Borchgrevink 2003; Susskind et al. 2000). In the model shown in Exhibit 1, we propose that standards act as a reminder for both coworkers and supervisors to support service providers. Consequently, we can conclude that having standards in place motivates service providers (employees and supervisors) to support one another in their work. 


\section{Guest Orientation}

For our purposes, we use the definition of guest orientation that focuses on the importance that service providers place on their guests' needs and the extent to which service providers are willing to put forth time and effort to satisfy their guests (Kelley 1992). By this definition, guest orientation is a key part of guest service, is influenced by interaction with the constituents of a service experience (e.g., guests, coworkers, and superiors) (Brady and Cronin 2001), and represents a service provider's level of commitment to his or her guests (Susskind, Kacmar, and Borchgrevink 2003; Susskind et al. 2000). Service providers who are proactive, anticipate their guests' needs, and are willing to go the extra mile for their guests would be considered guest oriented. Service providers who receive support from their coworkers and superiors while performing their duties are likely to show a stronger commitment to the service process and their guests, particularly when the supportive actions of others are based on the organization's standards for service delivery (Susskind, Kacmar, and Borchgrevink 2003; Susskind et al. 2000).

\section{Guest Satisfaction}

The end point of the model, guest satisfaction, is the desired outcome for servicerelated businesses, because of its contribution to profitability. To our surprise, only a limited number of research studies have examined the direct connection between employees' and guests' perceptions of the service process (see, for example, Brady and Cronin 2001; Johnson 1996; and Susskind, Kacmar, and Borchgrevink 2003). With this study, we examine the connection between service providers' attitudes and perceptions of their work-related duties and how those attitudes are connected to their guests' satisfaction with their service experiences. When service providers are committed to their role in the service process, they are more likely to consistently offer their guests better service.

\section{Study Details and Data Analyses}

We studied a total of 324 service employees from twenty-five units of a midwestern restaurant chain over a twomonth period. Forty percent of the linelevel participants were male, their median age was twenty-two (ranging between seventeen and forty-five), ${ }^{1}$ and they had worked for the company at the time of the survey for a median of just under twelve months (ranging from one month to ten years). ${ }^{2}$ To assess guest satisfaction in the restaurants, an average of eleven guests were surveyed from each of the twentyfive units we surveyed. In total, we collected 271 usable responses from guests. We surveyed an average of 12 employees from each of the twenty-five units (ranging from 6 to 24 employees per unit).

We evaluated the line-level employees' perceptions of standards using a questionnaire that had four items for service delivery, three items for coworker support, four items for supervisory support, and five items for guest orientation. Survey questions used 5point Likert-type scales with anchors ranging from strongly agree (5) to strongly disagree (1). The questionnaire items used and the scale reliabilities (Cronbach's $\alpha$ ) at the individual level are reported in the appendix. We then surveyed each restaurant's guests using a six-item questionnaire. (Again, see the appendix for the items used and the scale reliabilities.) The responses to employee and guest data were aggregated to

1. Median age $=22$ ( standard deviation $=5.14$ years $)$; mean age $=24.55$.

2. Median tenure $=12$ months (standard deviation $=20.32$ months ; mean $=18.76$ months . 
Exhibit 2:

Model of Guest Service Processes and Organizational Outcomes

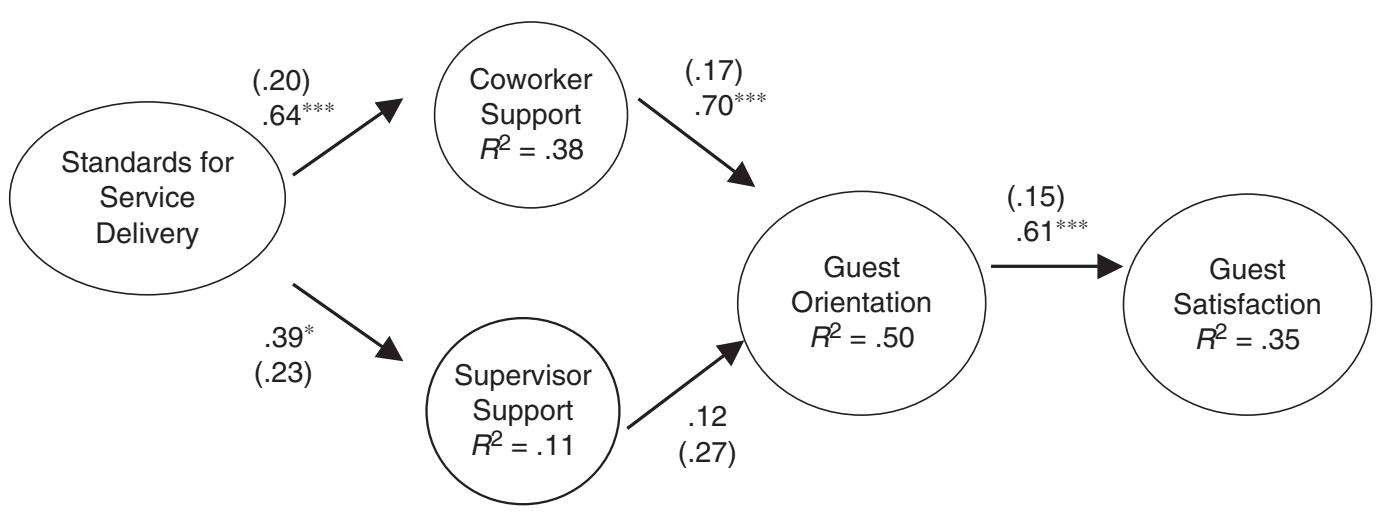

Note: The standard errors for the path coefficients appear in parentheses; the model was tested at the unit level. $* p<.05 . * * * p<.001$.

the organizational level. We made no attempt to match specific guest reactions to specific employees because multiple employees served each guest and some guests were in the restaurant during a shift change.

\section{Data Aggregation}

To offer sufficient support to aggregate these variables to the organizational level we examined the $r_{\mathrm{WG}(\mathrm{J})}$ statistic to determine within-organization agreement (James, Demaree, and Wolf 1984). This technique offers a measure of reliability within and across the units to ensure that aggregation of the data to the unit level is possible and appropriate. The $r_{\mathrm{WG}(\mathrm{J})}$ was computed for each scale, in each of the twenty-five units. The employees' responses from the twentyfive units aggregated to the organizational level exceed the recommended cutoff of .60 (James 1982). The statistics are as follows: $r_{\mathrm{WG}(4)}=.78$ for standards for service delivery, $r_{\mathrm{WG}(3)}=.77$ for coworker support, $r_{\mathrm{WG}(4)}=.73$ for supervisor support, and $r_{\mathrm{WG}(5)}=.92$ for guest orientation. Likewise, the guest satisfaction data yielded from the 271 guests from the twenty-five units were well suited to aggregation, indicating a high level of agreement $\left(r_{\mathrm{WG}(6)}=.96\right)$.

\section{Path Analysis}

The path model presented in Exhibit 2 was analyzed using least-squares static-path analysis to examine the direct and indirect effects of relationships presented in the model (Hunter and Hamilton 1995). Although path analysis does not establish causal relationships with certainty, it does provide quantitative interpretations of potential causal relationships (Borchgrevink and Boster 1998). In this case, the presence of servicedelivery standards was treated as the exogenous variable in the model, with coworker support, supervisory support, guest orientation, and guest satisfaction treated as the endogenous variables. The support functions were presented as mediators of the relationship between standards and guest orientation, and guest orientation was presented as a mediator between the support functions and guest satisfaction.

The path model was assessed for fit with the following specifications: (1) global chisquare tests for the sum of squared error for 


\section{Exhibit 3:}

Descriptive Statistics and Correlations from the Final Aggregated Scales at the Organizational Level

\begin{tabular}{lccccccr}
\hline & $\mathrm{M}$ & $\mathrm{SD}$ & 1 & 2 & 3 & 4 & 5 \\
\hline $\begin{array}{l}\text { 1. Standards for service } \\
\text { delivery }\end{array}$ & 3.64 & 0.38 & {$[.68]$} & & & & \\
2. Coworker support & 3.77 & 0.43 & $.43^{*}$ & {$[.74]$} & & & \\
3. Supervisor support & 3.47 & 0.47 & $.64^{* *}$ & .08 & {$[.68]$} & & \\
4. Guest orientation & 4.23 & 0.39 & $.49^{*}$ & $.63^{* *}$ & .24 & {$[.91]$} & \\
5. Guest satisfaction & 3.38 & 1.03 & $.48^{*}$ & $.59^{* *}$ & .30 & $.62^{* *}$ & {$[.96]$} \\
\hline
\end{tabular}

Note: $N=25$. The $r_{\mathrm{WG}(\mathrm{I})}$ aggregation statistic (James, Demaree, and Wolf 1984) is presented along the diagonal in brackets and represents the average across the 25 units in the company.

$* p<.05 . * * p<.01$.

the model are nonsignificant; (2) each path linkage in the model is tested for significance at the $p<.05$ level; and (3) sampling error analyses were conducted for each unspecified path in the model to rule out any misspecifications (Borchgrevink and Boster 1998).

\section{Study Results and Discussion}

\section{Test of the Proposed Model}

The test showed that the hypothesized model produced a good fit to the data, $\chi^{2}(5)=1.55, p=.90$. The descriptive statistics and correlations of the variables presented in the model are reported in Exhibit $3 .{ }^{3}$

In all twenty-five restaurants surveyed, employees and guests reacted similarly to the service environment they mutually created. This study shows that employees who reported high service standards indicated a strong presence of coworker support but a weaker level of supervisor support, which was then related to their perceptions of a guest orientation. In restaurants where employees reported a high level of guest orientation, guests reported a higher level of guest satisfaction with service. These findings confirm the results from a previously reported study that examined a broader range of service-based organizations (including restaurants, hotels, and retail stores) (Susskind, Kacmar, and Borchgrevink 2003).

A clear set of relationships emerged from the analyses. Guest satisfaction was related directly or indirectly to a number of service-related factors (as shown in Exhibit 3). Some of these factors are under management's control (notably, standards for service delivery and supervisory support), while others rest solely with the frontline service providers (including coworker support and guest orientation).

The test of the model in Exhibit 2 revealed three notable findings. First, perceptions of standards for service lay the foundation for how individuals view their jobs as service providers. In the model, support functions proved to be mediators of the relationship between standards for

3. To allay concerns over multicollinearity among the variables, as suggested by Nunnally and Bernstein (1994), we performed a principal-components factor analysis using a varimax rotation with the individuallevel data. The results show that the items loaded consistently on each of the four factors with no notable cross-loadings. The total variance explained by the measurement model was 75.72 percent. The scales are highly correlated, but based on the factor analyses, multicollinearity seems not to be a concern among these data. A copy of the factor analysis is available upon request from the first author. 
service and guest orientation. This means that standards alone are not sufficient to foster a guest orientation. The support and direction that emerge from standards are important to building a guest orientation among staff members. When perceived standards for service delivery were high, the findings showed that employees reported higher levels of support from both coworkers and supervisors. It should be noted, however, that the influence of standards on supervisor support was weaker than was the influence of standards on coworker support. ${ }^{4}$ What this suggests is that standards for service are fostered among coworkers more notably than are the standards among supervisors or managers. This observation is consistent with how the front line of a restaurant works. Although managers are present on the floor, the servers are the ones who must execute the service standards enunciated by managers. Although support from managers is weaker in the model than is support from coworkers, manager support is not insignificant and represents an important piece of the GSX.

Second, coworker support was significantly related to a server's guest orientation, while supervisor support was not. ${ }^{5}$ These findings suggest that the perceived presence of supportive coworkers in a service environment leads employees to a higher level of commitment to their guests. Once again, our findings indicate that restaurant employees need a supportive group of peers to help them perform service-related duties, while effusive supervisory support is not essential to a guest orientation. We suspect that coworker support contains distinctive elements that do not exist in the interaction of superiors and subordinates. This finding further reflects line-level employees' essential role in the GSX, since they are the ones interacting the most with guests. The observed relationships involving coworker and supervisor support indicate that servers view support functions relating to coworkers differently than they view support functions connected with their managers and supervisors (see Susskind, Kacmar, and Borchgrevink 2003). This finding confirms our belief that perceptions of support in a service environment come from multiple sources and that each type of support plays a different, but necessary role.

Last, guest satisfaction with service was strongly related to high levels of guest orientation, as reported by the servers and the guests in the restaurants. ${ }^{6}$ This is a result that all restaurateurs would believe to be true; service providers who demonstrate a strong commitment to their guests will make their guests happier than those servers who are less guest-focused. These findings suggest that when guest-oriented employees fulfill their role as service providers, they deliver excellent service to their guests, and in turn guests notice the service and report high satisfaction.

The study shows that standards account for about 38 percent of the variance in coworker support and 11 percent of the variance in supervisor support. We think that this is a promising finding for operators. That is, about half of the influence in support functions can be attributed to the reported presence of standards for service. The strong presence of standards is a key to developing cooperative behavior among servers. Of equal importance is the relationship between

4. $\beta=.64, p<.001, R^{2}=.38$ for the path between standards and coworker support; and $\beta=.39, p<.05$, $R^{2}=.11$ for the path between standards and supervisory support.

5. $\beta=.70, p<.001$, for the path between coworker support and customer orientation; and $\beta=.12, p=$ n.s. for the path between supervisory support and customer orientation with a combined $R^{2}=.50$ on customer orientation.

6. $\beta=.61, p<.001$, for the path between customer orientation and customer satisfaction, with an $R^{2}=.35$. 
support functions and guest orientation; 50 percent of the variance in guest orientation in this model is attributed to support functions, the bulk of which comes from coworkers. This suggests that camaraderie and support among the service staff is a key influence of being committed to guest service, with managerial and supervisory support being viewed as a peripheral element. Last, more than a third of the variance in guest satisfaction could be accounted for by servers' levels of guest orientation. This finding suggests that a large part of the guests' experience is influenced by the service they receive, but other elements (such as food, comfort, and ambience) likely have considerable influence on guest satisfaction as well. This model provides a good framework for operators to focus on elements in the GSX that lead to enhanced guest satisfaction.

\section{Managerial Implications}

For service standards to guide and direct employees, those standards need to be developed and articulated in a way that is generally accepted, clear, and understood by all employees. Training and organizational activities should emphasize the standards' specific goals and underlying rationale to ensure that they can be consistently achieved (Litwin and Stringer 1968). Servers will likely disregard standards that are viewed as unattainable or not pragmatic. Given the strong connection between standards and coworker and supervisor support, training, development, and management efforts should emphasize service standards whenever possible.

Another implication of our study relates to the role of the supervisor. Our study found that while supervisory support was an outgrowth of standards, support from the supervisor was not directly linked to service employees' reported guest orientation. This suggests that while the supervisor has an important role to play in clarifying and specifying service standards for employees and dealing with the service process at large, when it is time for service to occur, the supervisor should recognize that linelevel workers make or break the experience for the guest under normal circumstances. Therefore, supervisors should maintain a strong focus on the service standards as a way of helping line-level people deliver on those standards.

Our model suggests that a shared understanding of service standards, teamwork, and a guest orientation are important influences on guest satisfaction. Gaining a better understanding of how each element operates within the restaurant is a way to improve guests' service experiences.

\section{Limitations}

When designing the study, we knew that we would have to aggregate the data for each restaurant because we had no good way of collecting data that matched the results of individual employees and guests. Thus, the guests were not assessing their satisfaction with a specific employee but instead with their overall dining experience. The problem is that we then have a sample of just twenty-five restaurants. The sample size is a limitation, but one that we would face even if we surveyed two or three times as many restaurants in the chain without matched employee-andguest data. Limitations notwithstanding, this type of design and sampling methodology is common among field studies and studies of groups and teams where a single organization or a limited set of organizations is used. For example, Schneider et al. (2005) recently surveyed fifty-six departments in a national grocery chain, in a survey that drew a response rate of 40 percent. Researchers should continue to maximize sample size in their studies whenever possible 
but should not lose sight of the rich data that are available from smaller organizations, departments, or teams.

Last, while guest orientation accounted for roughly one-third of the variance in guest satisfaction in the restaurants we sampled, two-thirds of the variance remains unexplained through our model. This means that a guest-oriented service staff has a sizeable influence on guest satisfaction, but other factors that were not measured here have even greater influence on how guests react to their dining experiences. These influences should be identified and addressed in future studies.

\section{Next Steps}

The findings of this study highlight several directions for future research. First, it would be useful to test this model using additional guest-outcome measures such as intention to return, value perceptions, and satisfaction with other dimensions of the restaurant experience such as food, comfort, or ambience. Additionally, using measures of performance beyond guest satisfaction, such as employee performance or firm performance, could also shed more light on the pieces of the model presented here. Second, although it would be difficult to secure a matched sample of employee, managerial, and guest responses, it would be prudent to do so, to test this model entirely at the individual level of analysis.

In conclusion, this research shows the strong connection of employee behavior and attitudes with guest satisfaction. Given the dynamic nature of restaurant experiences, developing a better understanding of the elements that can be controlled and managed to improve the service process and perceived outcomes for guests is a key to improving restaurant performance.

\section{Appendix Listing of the Guest Service Attitude Questions}

Standards for Service Delivery Items $(\alpha=.87)$

1. The managers believe that well-trained guest-service employees are the key to providing excellent guest service in our restaurant.

2. In the restaurant I work for, we set very high standards for guest service.

3. Our management believes that no job is done so well that it couldn't be done better.

4. The managers believe that if we are happy, excellent guest service will result.

Coworker Support Items $(\alpha=.94)$

1. I find my coworkers very helpful when performing my guest-service duties.

2. When performing my service duties, I rely heavily on my coworkers.

3. My coworkers provide me with important work-related information and advice that make performing my job easier.

Supervisor Support Items $(\alpha=.95)$

1. I find my supervisor very helpful in performing my guest-service duties.

2. When performing my service duties, I rely heavily on my supervisor.

3. My supervisor provides me with important work-related information and advice that make performing my job easier.

4. I can count on my supervisor to do the "right thing" when serving guests. 


\section{Appendix (continued)}

Guest Orientation Items $(\alpha=.80)$

1. When performing my job, the guest is most important to me.

2. It is best to ensure that our guests receive the best possible service available.

3. If possible, I meet all requests made by my guests.

4. As an employee responsible for providing service, guests are very important to me.

5. I believe that providing timely, efficient service to guests is a major function of my job.

Guest Satisfaction with Service Items $(\alpha=.93)$

1. Overall, I am happy with the service I just received.

2. The employee(s) who assisted me seemed interested in providing excellent service.

3. The employee(s) who assisted me appeared happy to serve me.

4. The employee(s) performed their duties as I anticipated.

5. The employee(s) who assisted me appeared to be cold and distant.

6. This restaurant's employees really focus on guest service.

Source: Adapted from Susskind, Kacmar, and Borchgrevink (2003).

\section{References}

Armeli, S., R. Eisenberger, P. Fasolo, and P. Lynch. 1998. Perceived organizational support and police performance: The moderating influence of socioemotional needs. Journal of Applied Psychology 83:288-97.

Borchgrevink, C. P., and F. J. Boster. 1998. Leader-member exchange and interpersonal relationships: Construct validity and path model. Journal of Hospitality \& Leisure Marketing 5 (1): 53-80.

Brady, M. K., and J. J. Cronin. 2001. Customer orientation: Effects on customer service perceptions and outcome behavior. Journal of Service Research 3: 241-51.

Eisenberger, R., J. Cummings, S. Armeli, and P. Lynch. 1997. Perceived organizational support, discretionary treatment, and job satisfaction. Journal of Applied Psychology 82:812-20.

Ford, W. S. Z., and C. N. Etienne. 2003. Can I help you? A framework for interdisciplinary research on customer-service encounters. Management Сотmиnication Quarterly 7:413-41.

Grisaffe, D. 2000. Putting customer satisfaction in its place: Broader organizational research perspectives versus measurement myopia. Journal of Consumer Satisfaction, Dissatisfaction, and Complaining Behavior 13:1-16.

Hogan, J., R. Hogan, and C. M. Busch. 1984. How to measure service orientation. Journal of Applied Psychology 69:167-73

Hunter, J. E., and M. A. Hamilton. 1995. PATH: A program in BASICA. East Lansing: Michigan State University.

James, L. R. 1982. Aggregation bias estimates of perceptual agreement. Journal of Applied Psychology 67:219-29.
James, L. R., R. G. Demaree, and G. Wolf. 1984. Estimating within-group interrater reliability with and without response bias. Journal of Applied Psychology 69:85-98.

Johnson, J. 1996. Linking employee perceptions to customer satisfaction. Personnel Psychology 49:831-52.

Kelley, S. W. 1992. Developing customer orientation among service employees. Journal of the Academy of Marketing Science 20:27-36.

Litwin, G. H., and R. A. Stringer Jr. 1968. Motivation and organizational climate. Boston: Harvard University Graduate School of Business.

Nunnally, J. C., and I. H. Bernstein. 1994. Psychometric theory. 3rd ed. New York: McGraw-Hill.

Schmit, M. J., and S. P. Allscheid. 1995. Employee attitudes and customer satisfaction: Making theoretical and empirical connections. Personnel Psychology 48:521-36.

Schneider, B., M. G. Eirhart, D. M. Mayer, J. L. Saltz, and K. Niles-Jolly. 2005. Understanding organizationcustomer links in service settings. Academy of Management Journal 48:1017-32.

Schneider, B., S. S. White, and M. C. Paul. 1998. Linking service climate and customer perceptions of service quality: Test of a causal model. Journal of Applied Psychology 83:150-63.

Susskind, Alex M., Carl P. Borchgrevink, K. Michele Kacmar, and Robert A. Brymer. 2000. Customer service employees' behavioral intentions and attitudes: An examination of construct validity and a path model. International Journal of Hospitality Management 19 (1): 53-77.

Susskind, A. M., K. M. Kacmar, and C. P. Borchgrevink. 2003. Customer service providers' attitudes relating to customer service and customer satisfaction in the customer-server exchange (CSX). Journal of Applied Psychology 88 (1): 179-87.

Alex M. Susskind, Ph.D., is an associate professor of food and beverage management at the Cornell University School of Hotel Administration (ams76@cornell.edu). K. Michele Kacmar, Ph.D., is the DurrFillauer Chair of Business Ethics in the Culverhouse College of Commerce and Business Administration at the University of Alabama (mkacmar@cba.ua.edu). Carl P. Borchgrevink, Ph.D., is an associate professor at the School of Hospitality Business at Michigan State University (carlb@bus.msu.edu). 